\title{
Uptake and Cytotoxicity Characterization of Radioiodine in MCF-7 and SKBR3 Breast Cancer Cell Lines
}

\author{
A. Elliyanti ${ }^{1^{\star}}$, V.Y. Susilo ${ }^{2}$, S. Setiyowati ${ }^{2}$, M. Ramli $^{2}$, J.S. Masjhur ${ }^{3}$ and T.H. Achmad ${ }^{4}$ \\ ${ }^{I}$ Medical Physics/Radiology Department of Faculty of Medicine, Andalas University/Dr.M.Djamil Hospital \\ Jl. Perintis Kemerdekaan No. 94, Padang 25127, Indonesia \\ ${ }^{2}$ Center for Radioisotopes and Radiopharmaceutical Technology, National Nuclear Energy Agency, \\ Puspiptek Area, Serpong, Tangerang Selatan 15314, Indonesia \\ ${ }^{3}$ Department of Nuclear Medicine, Padjadjaran University, Bandung, Indonesia \\ ${ }^{4}$ Department of Biochemistry, Padjadjaran University, Bandung, Indonesia
}

\section{ARTICLE INFO}

\section{Article history:}

Received 4 October 2015

Received in revised form 14 August 2016

Accepted 2 September 2016

Keywords:

Breast cancer

Cell lines MCF-7 and SKBR-3

Radioiodine

Reproductive ability

Uptake

\begin{abstract}
A B S T R A C T
Radioiodine is an effective and low-risk therapy modality in well-differentiated thyroid cancer patients post near-total thyroidectomy. Extra thyroidal tumors such as breast cancer are known to be able to uptake radioiodine. The aim of this study was to analyze the uptake, efflux and cytotoxicity of radioiodine for two molecular types of breast cancer cell lines. Two types of breast cancer cell lines were used in this study, MCF-7 (luminal A type) and SKBR3 (HER2 type). The HaCaT cell line was used as normal cells. Iodine-125 (I-125) was used to measured radioiodine uptake and efflux. Clonogenic assay was used to assess cytotoxicity of iodine-131 (I-131) based on the tested cell reproductive ability. The radioiodine uptake in SKBR3 cells was found to be higher than that of MCF-7 and HaCaT cells at $p<0.05$. The reproductive ability of MCF-7 cells are lower than SKBR3 cells at $p<0.05$. Both breast cancer cells have less reproduction ability than HaCaT cells at $p<0.05$. Both types of breast cancer cells present the ability to uptake radioiodine and show a high sensitivity to radioiodine exposure. Normal cells also demonstrate an ability to uptake radioiodine. However, they have a better tolerance to the amount of I-131 exposure. These findings could potentially lead to the use if I-131 for ablative therapy in breast cancer, similiar to its use in the treatment of thyroid cancer.
\end{abstract}

\section{INTRODUCTION}

Breast cancer is a common malignancy among cancer patient women. As a systemic disease, it requires adjuvant therapy with hormone or anticancer drugs after surgery, with the aim to eliminate an occult micrometastatic disease and improving disease-free and overall survival [1]. However, anticancer drugs can be significantly toxic to normal cells. New anticancer drugs, which are selectively destructive to cancerous cells with minimum harmful effect to healthy ones, are

*Corresponding author.

E-mail address: aelliyanti@yahoo.com

DOI: http://dx.doi.org/10.17146/aij.2016.586 needed. Therefore, alternative therapeutic strategies targeting breast cancer cells selectively are the most promosing approach to achieve this aim. One of them is the radioiodine therapy. It has been used for well-differentiated thyroid cancer [2].

Radioiodine (I-131) has been used since 1946 in integrated management of thyroid cancer for adjuvant therapy. This is due to its ability to increase the rate of patient survival compared to patients who do not receive I-131 [3,4]. This therapy is based on the uptake of radioiodine into cancer cells. In thyroid cancer, the uptake of I-131 is affected by the natrium/iodide symporter (NIS) expression [3,5,6]. A natrium/iodide symporter brings two sodium ions $\left(\mathrm{Na}^{+}\right)$and one iodide ion (I) to cross the membrane against its ionic 
concentration gradient [3,6,7]. It serves as the driving force for iodide uptake and is maintained by $\mathrm{Na}^{+} / \mathrm{K}^{+}$-adenosine triphosphatase $\left(\mathrm{Na}^{+} / \mathrm{K}^{+}\right.$-ATPase $)$. Natrium iodide symporter activity is necessary to provide iodide accumulation inside thyroid cells $[6,7,9,14]$. Beside thyroid cancer cells, NIS is also expressed in above $80 \%$ of invasive breast cancer tissue samples [8].

Therefore, the same approach of treatment could also be applied to women with breast cancer because NIS is also expressed in breast cancer cells. In relation to cell surface of NIS expression with radioiodine uptake, there are varieties of cell surface NIS levels of breast cancer cells [9]. It is crucial to define the type of breast cancer cells that are potential to the radioiodine theraphy. The luminal $\mathrm{A}$ is a common breast cancer type and it has a good prognosis. On the other hand, the HER2 type has a poorer prognosis [10,11]. The characterization of radioiodine uptake and cytotoxic effects to cancer cells are important as a basis of the use of I-131 for breast cancer treatment. The aim of this study is to investigate the uptake, efflux, and cytotoxicity of radioiodine in the MCF-7 and SKBR3 cell lines which represent the luminal $A$ and HER2 breast cancer types, respectively.

\section{EXPERIMENTAL METHODS}

\section{Cell culture}

The SKBR3, MCF-7, and HaCaT cell lines were used in this study. The SKBR3 cell line was obtained from American Type Culture Collection (ATCC) through National Atomic Energy Agency (BATAN), Puspiptek Serpong. The MCF-7 and HaCaT cell lines were obtained from the Faculty of Medicine, Padjadjaran University, Bandung, Indonesia. The SKBR3 cell is HER2 positive, and the MCF-7 is a luminal A model [12]. The HaCaT line comprises normal keratin cells, and in this investigation they were used as a control.

The MCF-7 and HaCaT cells were cultured in RPMI 1640 medium (Sigma-Aldrich) while SKBR3 cells were cultured in McCoy's 5A medium (Sigma-Aldrich). All cell culture mediums were supplemented with $10 \%$ fetal bovine serum (Sigma-Aldrich), $1 \%$ penicillin, $1 \%$ streptomycin, and $1 \%$ amphotericin B. Cells were incubated at $37^{\circ} \mathrm{C}$ and supplied with 5\% of carbon dioxide $\left(\mathrm{CO}_{2}\right)$ until $80 \%$ confluency.

\section{Radioiodine uptake}

Twelve-well culture plates were seeded with MCF-7, SKBR3, and HaCaT cells. Assays were performed in triplicate. Cells were treated in Hanks' balanced salt solution (HBSS) (Gibco) and supplemented with $7.4 \times 10^{4}$ Becquerel/well of NaI-125 (BATAN, Indonesia), $10 \mathrm{mM}$ HEPES $\left(\mathrm{pH} 7.3\right.$ ) for 60 minutes at $37^{\circ} \mathrm{C}$, and $5 \% \mathrm{CO}_{2}$. The cells were rapidly washed twice with $1 \mathrm{~mL}$ cold HBSS and incubated in $1 \mathrm{~mL} \mathrm{95 \%} \mathrm{ethanol} \mathrm{at}$ room temperature for 20 minutes to release intracellular I-125. The supernatant was counted in a gamma radiation counter. The counts per minute were normalized to $10^{6}$ cell number. Untreated cells were used as a control. Due to its ability to emit low-energy gamma radiation, Iodine-125 was used for radioiodine uptake and efflux experiments [6]. This makes counting of uptake and efflux of radioiodine by gamma radiation counters possible.

\section{Radioiodine efflux}

Briefly, MCF-7, SKBR3, and HaCaT cells were incubated in HBSS and supplemented with $7.4 \times 10^{4} \mathrm{Becquerel} /$ well of NaI-125, $10 \mathrm{mM}$ HEPES $\left(\mathrm{pH} \mathrm{7.3)}\right.$ for 60 minutes at $37^{\circ} \mathrm{C}$, and $5 \% \mathrm{CO}_{2}$. The medium was replaced every $15 \mathrm{~min}$ with fresh HBSS, but without I-125. The content of I-125 in the collected supernatant was measured by gamma-counter. After the time end point (60 min), the cells were extracted with $1 \mathrm{~mL} \mathrm{95 \%} \mathrm{ethanol} \mathrm{to}$ count the residual radioactivity. The total uptake of each well was calculated as the sum of efflux washes and the lysate. These experiments were performed in triplicate.

\section{Clonogenic assay}

Briefly, MCF-7, SKBR3, and HaCaT cells were grown in twelve-well culture plates until $90 \%$ confluency. These experiments were performed in triplicate. The cells were then incubated for $7 \mathrm{~h}$ in $5 \% \mathrm{CO}_{2}$ at $37^{\circ} \mathrm{C}$ with $\mathrm{HBSS}$ containing $7.4 \times 10^{5}$ Becquerel/well NaI-131 (BATAN Indonesia), and $10 \mathrm{mM}$ HEPES ( $\mathrm{pH}$ 7.3). The reaction was terminated by removing the I-131 containing medium and the cells were washed twice with cold HBSS. The cells were then trypsinized, counted, and plated at densities of 500 and 1000 cells/well with growth medium in six-well culture plates. The cells were then grown for 10 days, washed with phosphate-buffered saline (PBS), fixed with methanol/water (1:1), and then stained with crystal violet. Macroscopic colonies were counted. 
The survival rate was calculated as the percentage of cell colonies in plates treated with I-131 compared with those treated with only HBSS. Iodine-131 was used for clonogenic assay. It emits beta particles which affect cell reproduction.

\section{Statistical analyses}

The data are expressed as mean \pm standard deviation (SD) when distributed normally. Data comparison between groups were made with one-way ANOVA, followed by Dunnett's T3 test, with $p$ values $<0.05$ being considered significant.

\section{RESULTS AND DISCUSSION}

\section{Radioiodine uptake}

The radioidodine uptakes of SKBR3 and MCF-7 cells are compared to that of HaCaT cells. SKBR3 cells' uptake is found to be significantly higher $(1765 \pm 44 \mathrm{kcpm})$ when compared with both MCF-7 and HaCaT cells at $p<0.05$, as shown in Fig. 1. An insignificant difference was found in radioiodine uptake between MCF-7 and $\mathrm{HaCaT}$ cells. In our study ( the data from our another study and do not publish yet), MCF-7 and $\mathrm{HaCaT}$ cells do not express NIS, which is needed as iodine co-transporter (unpublished data). It is assumed that the insignificant difference in radioidine uptake between MCF-7 and HaCaT cells is related to the absence of NIS expression in both cells. A high uptake of radioiodine by the cells is needed to reach the optimal effects of treatment. Nakamoto et al. 197 reported, based on their in-vitro study, that there are two ways to increase the uptake, first by increasing the iodine concentration and second by increasing the cells numbers [1]. Another study by Vadysirisack et al. also reported that radioiodine uptake could be elevated by increasing iodine concentration in the culture medium [13].

In our study ( the data from our another study and do not publish yet), NIS expression was only detected in SKBR3 cells (unpublished data). It was found that the radioiodine uptake in SKBR3 cells was higher than in MCF-7 cells. This might be attributed to NIS expression. Vadysirisack et al. reported that NIS level increases the radioiodine uptake. However, NIS cell-surface levels are not associated with degrees of radioiodide uptake among different cell types. It can be caused by cells differing in their membrane potential, $\mathrm{Na}^{+} / \mathrm{K}^{+}$gradient, influx/efflux kinetics, iodide organification, and so forth [13].
It has also been found in this study that the higher radioiodine uptake of SKBR3 cells, when compared with MCF-7 cells, can be attributed to having an association with the NIS presence in SKBR3 cells. Even though NIS expression cannot be detected in MCF-7 cells, an uptake of radioiodine can be counted in these cells. Furthermore, Joseph et al. also reported, from their study, that there was an uptake of radioiodine by NIS negative expression of breast cancer tissues [5]. It is subsequently assumed here that radioiodine uptake is not only dependent on NIS as co-transporter in breast cells. It is postulated that iodine transport in breast cells can be achieved through a passive transport beside of active transport with role of NIS as co-transporter. Further studies are required to determine whether this phenomenon occurs in vivo which is a different microenvironment from cell culture.

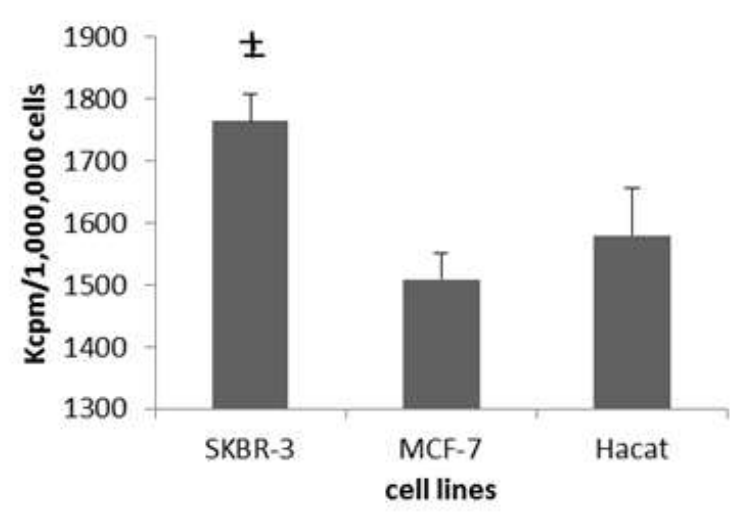

Fig. 1. Radioiodine uptake in SKBR3, MCF-7, and HaCaT cells.

Note: Each uptake was measured in $\mathrm{kcpm} / 10^{6}$ cells. The results are representative of triplicate wells. SKBR3 cells show a significantly higher I-125 uptake compared to MCF-7 and HaCaT cells.

\section{Radioiodine efflux}

Radioiodine uptake is essential for I-131 therapy effectiveness. The retention of radioiodine that is effected by iodine efflux is also important variable. Radioiodine effluxes were determined in SKBR3, MCF-7, and HaCaT cells. The cells exhibited a slow release during the first 15 minutes. After 60 minutes, the residual activity of I-125 had decreased to $60 \%, 77.3 \%$, and $83.4 \%$ in MCF-7, SKBR3, and HaCaT cells, respectively (see Fig. 2). Nakamoto et al.'s study reported that the radioiodine efflux of the MCF3B breast cancer cell line was slower than that of FRTL5 cells, as a representative of thyroid cells [1]. 


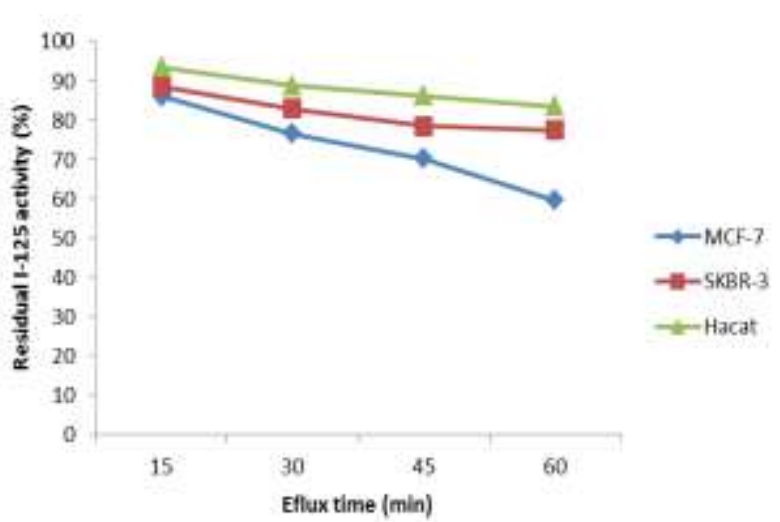

Fig. 2. Iodine efflux in SKBR3, MCF-7, and HaCaT cells after one hour of incubation with I-125.

Note: After the cells had been incubated, the buffer containing radioiodine was removed every 15 minutes and radioactivity was determined. Data are expressed as means of residual activity (\%) of I-125 of triplicate wells.

\section{Clonogenic assay}

The cytotoxic activity of I-131 was investigated with clonogenic assay, based on the reproductive abilities of SKBR3, MCF-7, and $\mathrm{HaCaT}$ cells. This assay has been used for more than 50 years which enables the assessment of different reproductive abilities in vitro between treated cells with untreated ones [15].

Iodine-131 treatment reduced reproductive ability in MCF-7 and SKBR3 cells $(p<0.05)$ as shown in Fig. 3. Reproductive ability was determined by counting the number of colonies generated after ten days of radioiodine exposure. The colony formations of SKBR3 cells were $42.1 \% \pm 3.6 \%$ and $52.6 \% \pm 8.5 \%$ for 500 and 1000 planted cells, respectively, while for MCF-7 cells they were $13.5 \% \pm 4.2 \%$ and $22.6 \% \pm 4.8 \%$ for 500 and 1000 planted cells, respectively. It was found that there was an insignificant difference in the generated number of colonies between 500 and 1000 planted SKBR3 and MCF-7 cells. It can be concluded that both breast cancer cell lines respond to radioiodine exposure. It is assumed here that one of the mechanisms of iodine-131 toxicity toward MCF-7 cells can be through a bystander effect. Further investigation is needed to determine the correctness of this assumption.

On the other hand, the formations of $\mathrm{HaCaT}$ cell colonies as response to I-131 were $99.6 \% \pm 5.5$ and $98.3 \% \pm 4.5 \%$ for 500 and 1000 planted cells, respectively. From this finding, it can be concluded that $\mathrm{HaCaT}$ as normal control cells do not become affected by radioiodine exposure. This study shows that the amount of uptake and efflux of radioiodine in HaCat cell does not relate to the cytotoxic effect. We need to add some explanation and make some changes that relate to cells, uptake and cytotoxicity as below:

Otherwise, SKBR3 showed a significantly higher uptake of radioiodine and reduced reproductive ability as shown in Fig 3. Interestingly, the MCF-7cell was found to be less uptake of radioiodine than in other cells. However, the radioiodine treatment showed a significantly reduce reproductive ability of the cell as shown in Fig. 3. It can be assumed that the two types of breast cancer cells might have different proapoptosis genes expression that can influence the sensitivity toward radioiodine exposure. Further investigations are still needed to examine this finding.

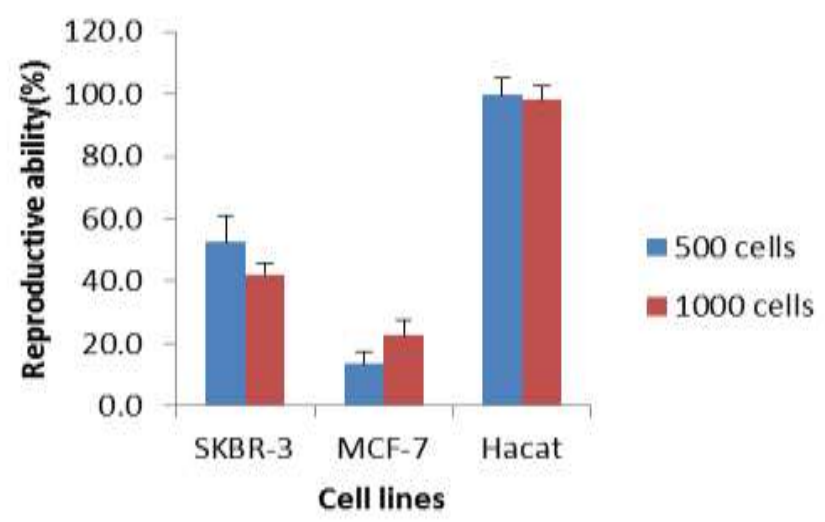

Fig. 3. Reproductive ability (\%) of SKBR3, MCF-7 and HaCaT cells after treatment with $20 \mu \mathrm{Ci} 7.4 \times 10^{5} \mathrm{~Bq} /$ well of I-131 for 7 hours at $37^{\circ} \mathrm{C}$. MCF-7 and SKBR3 cells have lower reproductive abilities than $\mathrm{HaCaT}$ cells at $p<0.05$.

The radioiodine exposure to $\mathrm{HaCaT}$ cells, as a normal control, show almost no influence to the reproductive ability of the cells. Extra-thyroid cells are reported also to be able to take up iodine-131, including salivary glands, stomach and lacrimal glands. However, radioiodine uptake in those cells can be tolerated well $[5,6]$.

Several factors influence the toxic effects in cells during radioiodine exposure, including the amount of uptake, retention time, and biological half life. Additionally, cell sensitivity toward radiation, which is influenced by microenvironment and proapoptosis genes expression, also plays an important role. These factors can influence the cells' response toward radioiodine exposure [16].

In this study, normal cells, which receive certain amount of radioiodine, did not show any toxic effect. Instead, it reduced the reproductive ability of MCF-7 and SKBR3 cells significantly. These results could indicate advantages for 
radioiodine as a therapy agent for breast cancer. Further studies are still needed in order to determine the role of radioiodine in reducing the reproductive ability of breast cancer cells.

\section{CONCLUSION}

The ability of the breast cancer cells in taking up radioiodine and suppressing cells reproductivity has led to a potential of I-131 to be used for ablative therapy in breast cancer which is analogous to its employment in the treatment of thyroid cancer. Further studies are required regarding the iodide transport in breast cells that is expected to be able to provide a new therapeutic pathway.

\section{ACKNOWLEDGMENT}

The authors thank Dr. Ahmad Farid who provided the MCF-7 and HaCaT cell lines, Tenny Kania Putri who help work with cell cultures, and Dr. Siti Darwati from National Nuclear Energy Agency, Kawasan Puspiptek, for facilitating this study. Part of this study was supported by the Doctorate Grant from the Directorate of Higher Education of Indonesia

\section{REFERENCES}

1. Y. Nakamoto, T. Saga, T. Misaki et al., J. Nucl. Med. 41 (2000) 1898.

2. D.A. Pryma and S.J. Mandel, J. Nucl. Med. 55 (2014) 1485.

3. B.C. Ahn, Theranostics 2 (2012) 392.

4. C. Reiners, M. Dietlein, F. Verbug et al., Ablation Therapy with Radioiodine in Adults and Children with Differentiated Thyroid Cancer, in: Therapeutic Nuclear Medicine, R.P.
Baum (Ed.), Springer-Verlag Berlin Heidelberg (2012) 245. DOI: 10.1007/174_2012_694

5. J.K. Joseph, R.B. Patel, A.A. Damle et al., Indian J. Surg. Oncol. 4 (2013) 80.

6. J.R. Oh and B.C. Ahn, Am. J. Nucl. Med. Mol. Imaging 2 (2012) 362.

7. J.K. Chung, Sodium Iodide Symporter in Thyroid Carcinoma, in: Therapeutic Nuclear Medicine, R.P. Baum (Ed.), DOI: 10.1007/174_2012_731, Springer-Verlag Berlin Heidelberg (2012) 225.

8. U.H. Tazebay, Regulation of the Functional $\mathrm{Na}^{+} / \mathrm{I}$ Symporter (NIS) Expression in Breast Cancer Cells, in: Breast Cancer-Recent Advances in Biology, Imaging and Therapeutics, Dr. Susan Done (Ed.), InTech, Croatia (2011) 103.

9. S.J. Beyer, X. Zhang, R.E. Jimenez et al., BMC Research Notes (2011) 392.

10. H.S. Kim, I. Park, H.J. Cho et al., J. Breast. Cancer 15 (2012) 401.

11. D.L. Holliday and V. Speirs, Breast Cancer Res. 13 (2011) 215.

12. P. Kim, X. Liu, T. Lee et al., Proteome Sci. (2011) 75 .

13. D.D. Vadysirisack, D.H. Shen and S.M. Jhiang, J. Nucl. Med. 47 (2006) 182.

14. S. Micali, S. Bulotta, C. Puppin et al., BMC Cancer 14 (2014) 303.

15. H. Rafehi, C. Orlowski, G.T. Georgiadis et al., J. Visualized Experiments (2011).

16. H.W. Kim, J.E. Kim, M.H. Hwang et al., Enhancement of Natural Killer Cell Cytotoxicity by Sodium/Iodide Symporter Gene-Mediated Radioiodine Pretreatment in Breast Cancer Cells, PLos One 8 (2013) dx.doi.org/10.1371/journal.pone.0070194. 